\title{
RELATIONSHIP BETWEEN EPISIOTOMY AND PREVALENCE OF URINARY INCONTINENCE IN WOMEN 2-5 YEARS AFTER CHILDBIRTH
}

\author{
Petra Langrová, Yvetta Vrublová \\ Department of Nursing and Midwifery, Faculty of Medicine, University of Ostrava, Czech Republic
}

Received December 4, 2013

Accepted March 10, 2014

\begin{abstract}
Aim: The aim of the study was to find a relationship between episiotomy and prevalence of urinary incontinence in women. The obtained results were compared with those in women who suffered 1st- or 2nd-degree perineal tears during childbirth and those with an intact perineum. Design: Cross sectional study. Methods: The sample was made up of 211 women, who were 2-5 years after a spontaneous term childbirth. The data were collected using the International Consultation on Incontinence Questionnaire - Short Form (ICIQ-SF). Results: No differences were found in the prevalence of urinary incontinence between women with episiotomy and those with spontaneous perineal tears or with an intact perineum. The prevalence of urinary incontinence is affected by a woman's BMI, parity and the presence of incontinence before childbirth. Conclusion: The study did not find episiotomy to either increase or decrease the prevalence of urinary incontinence at 2-5 years postpartum.
\end{abstract}

Key words: episiotomy, perineal tears, urinary incontinence, vaginal delivery, ICIQ-SF.

\section{Introduction}

Episiotomy is the most common obstetric surgical procedure performed in the second stage of labor. In the literature, episiotomy is classified into three types as follows: midline, mediolateral and lateral. The latter type is not much used today. Midline episiotomy is popular in the USA; in Europe, mediolateral episiotomy is most frequently carried out (Räisänen, Vehviläinen-Julkunen, Heinonen, 2010). Worldwide, episiotomy rates increased in the first half of the 20th century when childbirth moved from home to hospital in the majority of cases and episiotomy became a routine part of medically managed labor (Carroli, Mignini, 2009) Episiotomy was thought to decrease the risk of cerebral hemorrhage, birth asphyxia and shoulder dystocia in newborns. The incision was supposed to speed up birth, protect the perineum and rectum from large tears and reduce postnatal pain and fecal incontinence. It was meant to prevent injury to the pelvic floor and thus reduce problems with pelvic organ prolapse and urinary incontinence (Lappen,

Corresponding author: Petra Langrová, Department of Nursing and Midwifery, University of Ostrava, Syllabova 19, Ostrava, Czech Republic, e-mail: p.langrova@seznam.cz.
Gossett, 2010; Cleary-Goldman, Robinson, 2003). At that time, health practitioners considered episiotomy an effective tool for safe delivery and performed it routinely (Chang et al., 2011). It was not until the 1980 s that questions arose whether routine episiotomy was beneficial for women in labor (Cleary-Goldman, Robinson, 2003). Today, routine episiotomy is no longer recommended (Carroli, Mignini, 2009). Although the worldwide trend is toward reducing episiotomy rates, the prevalence varies significantly among countries as well as individual health facilities (Lappen, Gossett, 2010; Chang et al., 2011). In the Czech Republic, nearly 36,000 episiotomies were performed in 2012 (Rodička a novorozenec 2012, www.uzis.cz).

In clinical practice, episiotomy is most commonly indicated to preserve pelvic floor function (Rušavý et al., 2011). In women, pelvic floor disorders may lead to urinary incontinence. Therefore, we wanted to see if there were any differences in the prevalence and severity of urinary incontinence between women who had undergone episiotomy in labor, those with spontaneous perineal tears and women without perineal injury during childbirth. 


\section{Aim}

The study aimed at determining the impact of episiotomy on the prevalence of urinary incontinence in women. The obtained results were compared with those in women with spontaneous perineal tears and women without perineal injury during childbirth. Additionally, selected factors (age, parity, BMI and urinary incontinence before delivery) were studied to see if these could affect the development of urinary incontinence.

\section{Methods}

\section{Design}

A cross sectional study was conducted and a questionnaire was administered to women 2-5 years after birth.

\section{Sample}

The cohort comprised 211 women who had undergone spontaneous vaginal delivery 2 to 5 years previously. Another inclusion criterion was full-term birth. At the time of data collection, their age had to range from 21 to 48 years.

\section{Data collection}

The data were collected in 13 private gynecology offices in August and September 2013. To detect urinary incontinence, the International Consultation on Incontinence Questionnaire - Short Form (ICIQ$\mathrm{SF})$ was used. This measure contains 4 items for evaluating the frequency of incontinence, amount of leakage, impact on everyday life and activities leading to a loss of urine. The first three questions are scored on a scale. The overall score ranges from 0 to 21 , with 0 indicating no urinary incontinence. By contrast, higher scores suggest problems with urinary continence. The questionnaire was supplemented with additional questions on women's obstetric history and selected anthropometric data (body height and weight).

Prior to the survey, approval was obtained from the University of Ostrava Ethics Committee and informed consent was given by the gynecology office representatives. The questionnaires were handed to gynecology office staff who were explained the principles for data collection. Given the sensitivity of data, the questionnaires were put into envelopes. The enveloped questionnaires together with leaflets on the survey were made available in the office waiting rooms. Once filled in by the respondents, the questionnaires were reinserted into envelopes and put in marked boxes.

\section{Data analysis}

The data were processed using the SPSS version 15 statistical software. Nonparametric tests (the KruskalWallis test, Spearman rank correlation and MannWhitney U test) were used for the analysis; the Shapiro-Wilk test was used to check normality of the data. The test were performed at a significance level of 0.05 .

\section{Results}

The cohort comprised 211 respondents. Their mean age was 30.83 years and the mean body mass index (BMI) was 24.09. More than a half of the respondents were primiparous. The most frequent intervention performed during the last childbirth was episiotomy. Problems with urine leakage were reported by $44 \%$ of the respondents (Table 1).

Table 1 Characteristics of respondents

\begin{tabular}{lc}
\hline Characteristics & $\mathbf{N}(\%)$ \\
\hline Parity & $112(35)$ \\
primiparous & $89(56)$ \\
secundiparous & $10(9)$ \\
terciparous & \\
Perimeal trauma & $43(20)$ \\
intact perineum & $32(15)$ \\
1st-degree tear & $21(10)$ \\
2nd-degree tear & $3(1)$ \\
3rd-degree tear & $112(53)$ \\
episiotomy & \\
Problems with urine leakage & $118(56)$ \\
yes & $93(44)$ \\
no & \\
\hline
\end{tabular}

In the group of incontinent women, leakage of small amounts of urine once a week or less frequently was mostly reported. The most common activities leading

Table 2 Characteristics of respondents suffering from urine leakage

\begin{tabular}{lc}
\hline & $\mathbf{N}(\%)$ \\
\hline Urine leaking & $78(84)$ \\
once or less a week & $8(9)$ \\
two or three times a week & $5(5)$ \\
once a day & $2(2)$ \\
several times a day & $0(0)$ \\
constantly & \\
Amount of urine leaked & $90(98)$ \\
small & $2(2)$ \\
moderate & $0(0)$ \\
large & \\
Reasons for urinary leakage & $77(83)$ \\
cough, laugh, exercise, physical activity & $12(13)$ \\
before getting to a toilet & $4(4)$ \\
unknown &
\end{tabular}


to urine leakage were exercise, physical activity, coughing and sneezing (Table 2).

ICIQ-SF scores were compared between groups of women after episiotomy, those with intact perineum and those with spontaneous perineal tears (1st- or 2nd-degree tears). Third-degree tears were not evaluated because of a small sample size (3 respondents). The classification was made according to the last childbirth. There were no statistically significant differences in the presence or severity of urinary incontinence between the groups (Table 3).

Table 3 Perineal trauma, interventions and ICIQ-SF scores

\begin{tabular}{lcccc}
\hline & N & $\begin{array}{c}\text { Min- } \\
\text { Max }\end{array}$ & Median & Mean \\
\hline Intact perineum & 43 & $0-16$ & 0 & 3.7 \\
1st-degree tear & 32 & $0-13$ & 4 & 3.8 \\
2nd-degree tear & 21 & $0-13$ & 0 & 4.9 \\
Episiotomy & 112 & $0-16$ & 0 & 3.4 \\
Kruskal-Wallis & & $\mathrm{p}=0.675$ & \\
test significance & & & \\
\hline
\end{tabular}

The test was also performed in the group of primiparous women to prevent bias due to injuries during previous childbirths. Once again, there were no statistically significant differences in the presence or severity of urinary incontinence between women without labor trauma, those with spontaneous perineal tears and those with episiotomy when assessing the group of primiparous individuals (Table $4)$.

Table 4 Perineal trauma, interventions and ICIQ-SF scores in primiparas

\begin{tabular}{lcccc}
\hline & N & $\begin{array}{c}\text { Min- } \\
\text { Max }\end{array}$ & Median & Mean \\
\hline Intact perineum & 21 & $0-13$ & 0 & 3.8 \\
1st-degree tear & 8 & $0-8$ & 0 & 1.5 \\
2nd-degree tear & 11 & $0-13$ & 0 & 2.4 \\
Episiotomy & 69 & $0-16$ & 0 & 3.4 \\
Kruskal-Wallis & & $\mathrm{p}=0.671$ & \\
test significance & \multicolumn{5}{c}{} \\
\hline
\end{tabular}

A sub-objective of the study was to ascertain whether certain variables may have an impact on urinary incontinence. Spearman rank correlation found a weak correlation between respondents' BMI values and ICIQ-SF scores $(\mathrm{p}=0.015, \mathrm{r}=0.167)$. Women with higher BMI were more frequently incontinent of urine than women with lower BMI. Spearman rank correlation did not confirm a correlation between respondents' ages and ICIQ-SF scores $(\mathrm{p}=0.469, \mathrm{r}=$ 0.050). Primiparous respondents were less likely to have urinary incontinence than those who gave birth two or three times $(p=0.022)$. Problems with urine leakage prior to childbirth had a very significant impact $(\mathrm{p}<0.0001)$ on the development of urinary incontinence 2-5 years postpartum (Graph 1).

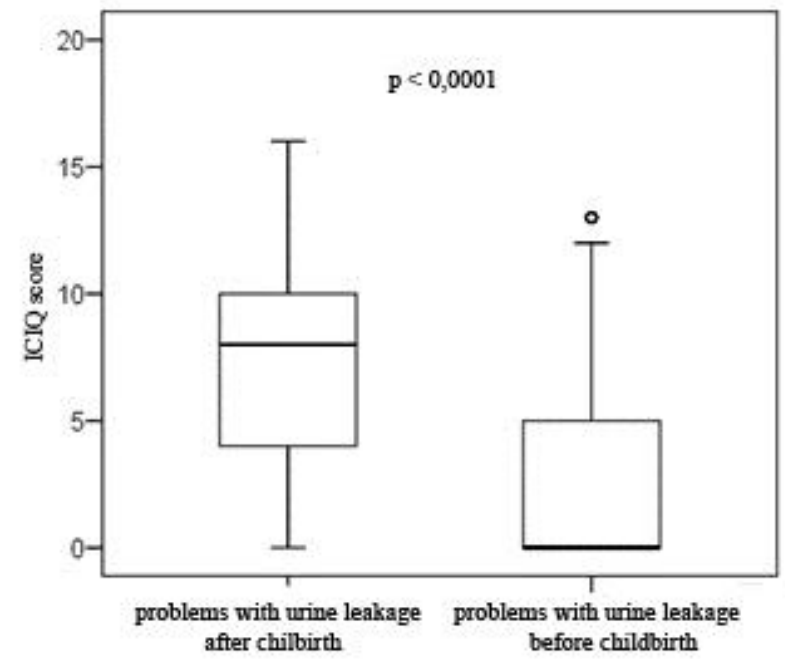

Graph 1 ICIQ-SF scores in respondents with or without problems with urinary continence prior to childbirth

\section{Discussion}

The study aimed at assessing the relationship between episiotomy and urinary incontinence in women 2-5 years postpartum. Four groups of women were compared: those with episiotomy, no labor trauma and 1st- and 2nd-degree spontaneous perineal tears. No differences in the presence or severity of urinary incontinence were found between the groups.

The impact of episiotomy on urinary incontinence remains controversial. For example, Chang et al. (2011) found that women who delivered with episiotomy had significantly higher urinary incontinence scores at 3 months postpartum than those without episiotomy. A negative effect of mediolateral episiotomy on urinary incontinence at 6 months postpartum was shown in a study by Yang et al. (2010) and as long as 5 years postpartum in a study by Viktrup and Lose (2001). Stress incontinence, the most common form of postpartum urinary incontinence, is closely related to pelvic floor muscle function. By 6 months postpartum, women with episiotomy decreased perineal muscle function more than those with an intact perineum or 1st- and 2nd-degree spontaneous perineal tears (Fleming, Newton, Roberts, 2003). By contrast, many other authors did not confirm the negative impact of episiotomy on urinary incontinence in their studies (Kessel et al., 2001; Arrue et al., 2010; Schytt, Lindmark, Waldenström, 2004; Arya et al., 2001; 
Foldspang, Mommsen, Djurhuus, 1999; Herrmann et al., 2009; Ali, Lakhani, Sarwar, 2013).

In the present study, problems with urine leakage prior to delivery were the most important factor for urinary incontinence. Urine leakage in pregnancy increases the risk for urinary incontinence at 6 months (Arya et al., 2001; Burgio et al., 2007) and at 4 years postpartum (Fritel et al., 2004).

The present study found lower rates of urinary incontinence in primiparous women than in those who gave birth two or three times. According to a longitudinal study by MacArthur et al. (2006), increasing numbers of births are associated with long-term urinary incontinence. Several authors have already reported a relationship between parity and urinary incontinence (Rortveit et al., 2003; Schytt, Lindmark, Waldenström, 2004; Marshall et al., 1996; Herrmann et al., 2009).

In the present study, women with higher BMI were more frequently incontinent of urine than women with lower BMI. Optimal body weight is very important for women. Postpartum urinary incontinence is affected by a woman's body weight after delivery (Schytt, Lindmark, Waldenström, 2004), prior to delivery (Yang et al., 2010) as well as before conception (Eftekhar et al., 2006). Postpartum weight loss decreases the risk of urinary incontinence (Hernández et al., 2013).

Although the prevalence of urinary incontinence increases with age (Minassian, Drutz, Al-Badr, 2003), the relationship between women's age and urinary incontinence was not confirmed by the present study. The association was reported by Rortveit et al. (2003). In their study, however, no upper age limit was defined and the cohort comprised women aged 20 or more years. Therefore, the respondents' mean age was different from that in our study, which was quite similar to the mean age of subjects in a study by Arrue et al. (2010). But their study found no correlation between age and postpartum urinary incontinence.

\section{Conclusion}

The study did not find episiotomy to either increase or decrease the prevalence of urinary incontinence. Therefore, performing episiotomy to protect pelvic floor function is not warranted. On the other hand, the main factor for urinary incontinence present at 25 years postpartum was the prevalence of problems with urine leakage before delivery. Thus, women should be informed about urinary incontinence both before pregnancy and prior to delivery. Moreover, they should be specifically asked about problems with urine leakage.

\section{Ethical aspects and conflict of interest}

Prior to the study, approval was obtained from the University of Ostrava Ethics Committee and written informed consent was given by the private gynecology office representatives.

\section{Acknowledgements}

With support from grant SGS 13/LF/2013 from the Faculty of Medicine, University of Ostrava.

\section{References}

Ali HS, Lakhani NA, Sarwar NG. Urinary incontinence three months after delivery; prevalence and risk factors. Professional Medical Journal. 2013;20(4):530-536.

Arrue M, Ibañez L, Paredes J, Murgiondo A, Belar M, Sarasqueta C, Diez-Itza I. Stress urinary incontinence six months after first vaginal delivery. European Journal of Obstetrics \& Gynecology and Reproductive Biology. 2010;150(2):210-214.

Arya LA, Jackson ND, Myers DL, Verma A. Risk of newonset urinary incontinence after forceps and vacuum delivery in primiparous women. American Journal of Obstetrics and Gynecology. 2001;185(6):1318-1324.

Burgio KL, Borello-France D, Richter HE, FitzGerald MP, Whitehead W, Handa VL, Nygaard I, Fine P, Zyczynski H, Visco AG, Brown MB, Weber AM. Risk factors for fecal and urinary incontinence after childbirth: the childbirth and pelvic symptoms study. American Journal of Gastroenterology. 2007;102(9):1998-2004.

Carroli G, Mignini L. Episiotomy for vaginal birth. The Cochrane Database of Systematic Review. 2009;1.

Chang SR, Chen KH, Lin HH, Chao YM, Lai YH. Comparison of the effects of episiotomy and no episiotomy on pain, urinary incontinence, and sexual function 3 months postpartum: A prospective follow-up study. International Journal of Nursing Studies. 2011;48(4):409-418.

Cleary-Goldman J, Robinson N. The role of episiotomy in current obstetric practice. Seminars in Perinatology. 2003;27(1):3-12.

Eftekhar T, Hajibaratali B, Ramezanzadeh F, Shariat M. Postpartum evaluation of stress urinary incontinence among primiparas. International Journal of Gynecology \& Obstetrics. 2006;94(2):114-118.

Fleming N, Newton ER, Roberts J. Changes in postpartum perineal muscle function in women with and without episiotomies. Journal of Midwifery \& Women's Health. 2003;48(1):53-59.

Foldspang A, Mommsen S, Djurhuus JC. Prevalent urinary incontinence as a correlate of pregnancy, vaginal childbirth, and obstetric techniques. American Journal of Public Health. 1999;89(2):209-212.

Fritel X, Fauconnier A, Levet C, Bénifla L. Stress urinary incontinence 4 years after the first delivery: a retrospective cohort survey. Acta Obstetricia et Gynecologica Scandinavica. 2004;83(10):941-945.

Hernández RRV, Aranda ER, Aznar CT. Urinary incontinence and weight changes during pregnancy and postpartum: A pending challenge. Midwifery. 2013;29(12):123-129. 
Herrmann V, Scarpa K, Palma PCR, Riccetto CZ. Stress urinary incontinence 3 years after pregnancy: correlation to mode of delivery and parity. International Urogynecology Journal. 2009;20(3):281-288.

Kessel KV, Reed S, Newton K, Meier A, Lentz G. The second stage of labor and stress urinary incontinence. American Journal of Obstetrics and Gynecology. 2001;184(7):1571-1575.

Lappen JR, Gossett DR. Changes in episiotomy practice: evidence-based medicine in action. Expert Review of Obstetrics \& Gynecology. 2010;5(3):301-309.

MacArthur C, Glazener CMA, Wilson PD, Lancashire RJ, Herbison GP, Grant AM. Persistent urinary incontinence and delivery mode history: a six-year longitudinal study. BJOG: An International Journal of Obstetrics \& Gynaecology. 2006;113(2):218-224.

Marshall K, Totterdal D, McConnell V, Walsh DM, Whelan M. Urinary incontinence and constipation during pregnancy and after childbirth. Physiotherapy. 1996;82(2):98-103.

Minassian VA, Drutz HP, Al-Badr A. Urinary incontinence as a worldwide problem. International Journal of Gynecology and Obstetrics. 2003;82(3):327-338.

Räisänen S, Vehviläinen-Julkunen K, Heinonen S. Need for and consequences of episiotomy in vaginal birth: a critical approach. Midwifery. 2010;26(3):348-356.
Rodička a novorozenec 2012. Praha: Ústav zdravotnických informací a statistiky České republiky. (in Czech)

Rortveit G, Daltveit AK, Hannestad YS, Hunskaar S. Vaginal delivery parameters and urinary incontinence: The Norwegian EPINCONT study. American Journal of Obstetrics and Gynecology. 2003;189(5):1268-1274.

Rušavý Z, Kališ V, Landsmanová J, Kašová L, Karbanová J, Dolejšová K, Sýkora T, Nečesalová P, Novotný Z. Perineální audit: důvody pro vice než 1000 epiziotomií. Česká gynekologie. 2011;76(5):378-385. (in Czech)

Schytt E, Lindmark G, Waldenström U. Symptoms of stress incontinence 1 year after childbirth: prevalence and predictors in a national Swedish sample. Acta Obstetricia et Gynecologica Scandinavica. 2004;83(10):928-936.

Viktrup L, Lose G. The risk of stress incontinence 5 years after first delivery. American Journal of Obstetrics and Gynecology. 2001;185(1):82-87.

Yang X, Zhang HX, Yu HY, Gao XL, Yang HX, Dong Y. The prevalence of fecal incontinence and urinary incontinence in primiparous postpartum Chinese women. European Journal of Obstetrics \& Gynecology and Reproductive Biology. 2010;152(2):214-217. 